\title{
Association of gene polymorphisms in MYH11 and TGF- $\beta$ signaling with the susceptibility and clinical outcomes of Debakey type $₫$ aortic dissection
}

\section{Yafei Chang}

Sun Yat-sen University Zhongshan School of Medicine

\section{Qinghua Yuan}

The Seventh Affiliated Hospital Sun Yat-sen University

Peipei Jiang

The Fourth People's Hospital of Urumqi City

\section{Ling Sun}

Fuyang Tumor Hospital

\section{Yitong Ma}

First Affiliated Hospital of Xinjiang Medical University

\section{Xiang Ma ( $\square$ maxiangxj@yeah.net)}

First Affiliated Hospital of Xinjiang Medical University https://orcid.org/0000-0002-5840-8581

Primary research

Keywords: aortic dissection, MYH11, TGF- $\beta$, SNP, GMDR

Posted Date: March 17th, 2021

DOl: https://doi.org/10.21203/rs.3.rs-302078/v1

License: (9) (i) This work is licensed under a Creative Commons Attribution 4.0 International License. Read Full License 


\section{Abstract}

Background: Myosin heavy chain 11 (MYH11) and transforming growth factor- $\beta$ (TGF- $\beta$ ) signaling-related genes as the regulation of the structure and function of vascular smooth muscle cells (VSMCs) play a key role in the pathogenesis of aortic dissection (AD). This study aims to investigate the association of MYH11 and TGF- $\beta$ signaling-related gene polymorphisms with the susceptibility of DeBakey type III AD and its clinical outcomes.

Methods: A total of 159 patients with DeBakey $₫ A D$ and 305 healthy subjects were enrolled in this study. 4 SNPs (MYH11 rs115364997, rs117593370, TGFB1 rs1800469 and TGFBR1 rs1626340) were selected and analyzed. GMDR was used to evaluate gene-gene and gene-environment interactions. Patients were followed up for a median of 55.7 months.

Results: MYH1 1 rs115364997 G carriers (OR $=1.629 ; 95 \% \mathrm{Cl}$ : $1.077-2.462, P=0.020)$ or TGFBR1 rs1626340 A carriers (OR = 1.500; 95Cl: 1.032-2.181, $P=0.033$ ) had a higher risk of DeBakey type $\otimes A D$. MYH11, TGFB1, TGFBR1, and environment interactions are contribute to DeBakey type $\triangle A D$ risk (CVC=10/10, $P=0.001)$. Dominant models of MYH11 rs115364997 AG+GG genotype (HR = 2.443; 95\%Cl:1.096-5.445, $P=0.029)$, TGFB1 rs1800469 AG+GG (HR = 2.303; 95\%Cl:1.069-4.96, $P=0.033)$ were associated with a higher risk of mortality in DeBakey type III AD. TGFB1 rs1800469 dominant model AG+GG genotype was associated with a higher risk of recurrence of chest pain in DeBakey type III AD (HR $=1.566 ; 95 \% \mathrm{Cl}: 1.018-2.378, P=0.041)$.

Conclusions: This study indicated that variations of MYH11 rs115364997 and TGFBR1 rs1626340 are associated with genetic predisposition of DeBakey type III AD. G carriers of MYH11 rs115364997 or TGFB1 rs1800469 may be the poor prognostic indicators of mortality and recurrent chest pain in DeBakey type III AD. The interactions of gene-gene and gene-environment are associated with the risk of DeBakey type III AD.

\section{Introduction}

Aortic dissection (AD) is an acute disease with rapid progress and high mortality [1]. In the natural course, the mortality rate is as high as $50 \%$ within 48 hours [2]. The main pathological basis of $A D$ is the degenerative change in the medial layer of the aorta [3]. The abnormal phenotypic transformation and systolic dysfunction of vascular smooth muscle cells (VSMC) in the medial layer of the aorta driven by multiple gene mutation are the main pathogenesis of $A D[4,5]$.

Myosin heavy chain protein 11 (MYH11) gene encodes smooth muscle myosin heavy chain [6]. Myosin, as a specific contractile protein of SMCs, links with adhesion spot protein and constitutes the main component of elastin-contractile unit of SMC. Elastin-contractile unit conducts the mechanical force between elastin fiber and VSMCs, and it is also the micro-unit of pressure sensing device of aortic wall [7]. The elastin-contractile unit in the SMC plays a role in connecting the elastic fibers outside the cell and the contraction skeleton inside the cell. Mutations in genes encoding structural or functional proteins in this 
elastic-contractile unit can cause aortic aneurysm or dissection. Previous studies suggested that MYH11 genetic mutation causes familial thoracic aortic aneurysm and dissection (FTAAD) [8]. MYH11[9] (IVS32+1G>A) mutation affected the classical splicing site sequence causing the conformational change of a-helix domain of myosin heavy chain, and damaging the movement function of myosin. The destruction of elastin-contractile unit structure of smooth muscle leads to the abnormal contraction function of smooth muscle or the pressure sensing function of aorta, which can induce aortic diseases. However, there are few studies on MYH11 genetic and sporadic aortic dissection.

Transforming growth factor- $\beta$ (TGF- $\beta$ ) is a multi-functional cytokine that is crucial for vascular development, and regulates VSMC plasticity in mature and to maintain the stability of arterial walls [10]. The SMCs are in a static non-migration state in normal, with the contractile phenotype dominant, and TGF- $\beta$ signaling induces differentiation in VSMC and regulates the interaction of cells with extracellular matrix [11]. However, excessive TGF- $\beta$ signaling affects the structure of the smooth muscle in the medial layer of the aorta, then promotes aortic aneurysm/dissection, including Marfan syndrome and LoeysDietz syndrome. The paradoxical upregulation of TGF- $\beta$ signaling induces the phenotypic transformation of VSMCs from contractile type to syncytial type by regulating the expression of differentiation markers of VSMCs $[12,13]$. This leads to the proliferation and migration of SMC, a large amount of extracellular matrix secretion and synthesis, and the elastic fiber ruptured [14]. Previous studies suggested that mutations in genes encoding various components of the TGF- $\beta$ signaling cascade leads to TGF- $\beta$ vasculopathies of aortic diseases [15,16]. Yang $P$ et al. [17] used an inducible Cre-loxP system driven by a MYH11 promoter to delete TGF- $\beta$ type I receptor (Tgfbr1) in SMCs, the mice rapidly formed serious aortic dissection. Therefore, the importance of TGF- $\beta$ signaling in vascular diseases is mainly reflected in smooth muscle contraction pathway.

MYH11 and TGF- $\beta$ pathway-related gene variations are involved in the occurrence of aortic diseases by affecting the structure and function of aortic SMC. However, the interaction between MYH11 and TGF- $\beta$ pathway-related genetic polymorphisms in DeBakey type III AD is controversial. Therefore, this study aims to explore the association of MYH11, TGFB1 and TGFBR1 genetic polymorphisms, gene-gene and geneenvironment interaction with susceptibility and clinical outcome of Debakey type $₫ A D$.

\section{Material And Methods}

\section{Subjects}

This study was approved by the ethics committee of the First Affiliated Hospital of Xinjiang Medical University and implemented in accordance with the Helsinki declaration. All participants provided informed consent.

All subjects were from the First Affiliated Hospital of Xinjiang Medical University from January 2013 to December 2016. In this study, 173 patients with DeBakey type III AD were recruited as case group. All these patients received thoracic endovascular aortic repair (TEVAR) and continued treatment after surgery. 335 normal subjects from health examination center of the same hospital as control group. The 
information of all subjects was counted about age, gender, history of hypertension, diabetes, coronary heart disease, cerebrovascular disease, heart valve disease, BMI (body mass index), history of smoking and drinking. Then, we measured their white blood cell, blood urea nitrogen, creatinine, uric acid, glycosylated serum protein, triglyceride, total cholesterol, high density lipoprotein cholesterol, low density lipoprotein cholesterol.

\section{SNP selection}

Tag SNPs were screened according to Haploview software version 4.2 and National Center for Biotechnology Information SNP database (http://www.ncbi.nlm.nih.gov/SNP). The standard is minimum allele frequency $\geq 0.05$ and $R^{2} \geq 0.8$, referencing data on the Han Chinese population in Beijing, China. Four tag SNPs were selected, rs115364997 and rs 117593370 of MYH11, rs1800469 of TGFB1, and rs1626340 of TGFBR1.

\section{DNA extraction and Genotyping}

Blood samples were collected using the standard venipuncture technique. DNA was extracted from peripheral blood leukocytes using a whole blood genome DNA extraction kit (Beijing BiotekeCo. Ltd. Beijing, China). SNPs genotyping was performed using chain reaction-restriction fragment length polymorphism analysis as described previously.

\section{End Points}

Patients were followed up clinically for a median of 55.7 (47.6-7.9) months. The study was terminated in December 2019. The information was obtained from their inpatient or outpatient records or by telephone calls. The primary end point was death due to recurrence of aortic dissection, and the secondary end point was hospitalization for chest pain recurrence.

\section{Statistics}

Measurement data were shown as means \pm standard deviation, and the differences between case and control subjects were evaluated by independent-sample t-test. Hardy-Weinberg equilibrium, frequency distribution of genotype and allele was tested by $\chi 2$ test. The risks were expressed by odds ratio (OR) and $95 \%$ confidence interval $(\mathrm{Cl})$. The association of gene polymorphisms with survival outcomes and chest pain recurrence were performed by the Kaplan-Meier method, the log-rank test, univariate or multivariate Cox proportional hazards regression models. The risks were expressed by hazard ratio (HR) and $95 \% \mathrm{Cl}$. SPSS software version 22.0 (SPSS Inc., USA.) was used for this analysis. The figures were made using GraphPad prism 9.0 (GraphPad Software Inc., San Diego, CA, USA). Gene-gene and gene-environment interactions was analysis by generalized multifactor dimensionality reduction (GMDR), as described previously [18]. The best model is defined as the model with the maximum values of cross validation consistency (CVC) and the sign test, and $P<0.05$. 


\section{Results}

\section{Characteristics of participants}

The General characteristics of study participants were shown in Table 1. A total of 173 patients with DeBakey type III AD and 335 normal subjects were enrolled in the study. There were 144 males and 29 females in case group, with an average age of $51.54 \pm 11.53$ years. In control group, there were 193 males and 142 females, with an average age of $57.12 \pm 11.39$ years. There were significant differences between the case and control groups: systolic blood pressure (SBP, $P<0.001)$ diastolic blood pressure (DBP, $P<0.001$ ), body mass index (BMI, $P<0.001$ ), white blood cell (WBC, $P<0.001)$, blood urea nitrogen $(P=0.053)$, creatinine $(P=0.003)$, uric acid $(P=0.005)$, glucose $(P<0.001)$, glycosylated serum protein (GSP, $P<0.001)$, high density lipoprotein cholesterol $(P<0.001)$, hypertension $(P<0.001)$, diabetes $(P=$ $0.035)$, smoking $(P<0.001)$ and drinking $(P<0.001)$. There were not significantly different between case and control groups including triglyceride $(P=0.854)$, total cholesterol $(P=0.935)$, low density lipoprotein cholesterol $(P=0.692)$.

\section{The genotype and allele frequencies}

The genotype and allele distribution characteristics of SNPs in case and control group were shown in Table 2. The genotype distributions of 4 SNPs for both case and control participants were in accordance with the Hardy-Weinberg equilibrium. The genotype frequencies of MYH11 rs115364997 $(P=0.044)$, TGFBR1 rs1626340 $(P=0.030)$ and the allele frequencies of MYH11 rs115364997 $(P=0.011)$ were difference between case and control group. The genotype frequencies of MYH11 rs117593370, TGFB1 rs1800469, allele frequencies of MYH11 rs117593370, TGFB1 rs1800469 and TGFBR1 rs1626340 did not differ between the case and control groups $(P>0.05)$.

\section{Analysis of the association between genetic models and aortic dissection risk}

We further assessed the association between genetic models and the risk of Debakey type $\triangle A D$. MYH11 rs115364997 dominant model $A G+G G$ genotype $(O R=1.629 ; 95 \% \mathrm{Cl}: 1.077-2.462, P=0.020)$ and TGFBR1 rs1626340 dominant model GA+AA genotype (OR $=1.500 ; 95 \mathrm{Cl}: 1.032-2.181, P=0.033)$ were found to be the risk factors for AD. But there was no difference on genotypes of MYH11rs117593370, TGFB1rs1800469 $(P>0.05)$ (Table 3).

\section{Gene-gene interaction}

GMDR was used to analyze the interaction of the four SNPs (Table 4). The best model is the two-factor interaction model of MYH11 rs115364997 and TGFBR1 rs1626340 with the maximum CVC (10/10) after 1000 permutation tests, and the maximum values of sign test (10) and testing balance accuracy (0.5600), $P=0.0010$.

\section{Geneenvironment interaction}


GMDR was used to analyze the association between gene-environment interaction and AD risk (Table 5). Possible risk factors including the four SNPs, smoking, drinking, hypertension, type 2 diabetes, BMI $\geq$ $24 \mathrm{~kg} / \mathrm{m}^{2}$ and dyslipidemia were considered in the model. The best model is the seven-factor interaction model of MYH11rs115364997, TGFB1rs1800469, TGFBR1rs1626340, smoking, drinking, hypertension, $\mathrm{BMI} \geq 24 \mathrm{~kg} / \mathrm{m}^{2}$ with the maximum CVC (10/10) after 1000 permutation tests, and the maximum values of sign test (10) and testing balance accuracy (0.7673), $P=0.0010$. The potential interaction of drinking and $\mathrm{BMI} \geq 24 \mathrm{~kg} / \mathrm{m}^{2}$ on type III $\mathrm{AD}$ risk was discovered $(\mathrm{CVC}=10 / 10 ; P=0.0010)$. In addition, we found that the two-factor, six-factor, and eight-factor models are also statistically significant $(P=0.0010)$ and maximum cross-validation consistency (10/10). However, compared with the seven-factor model, these models have lower values of test balance accuracy.

\section{Associations of 4 SNPs with clinical outcomes in Debakey type $₫$ aortic dissection patients}

At the end of the study, a total of 28 patients died of recurrence of aortic dissection, and 94 patients had

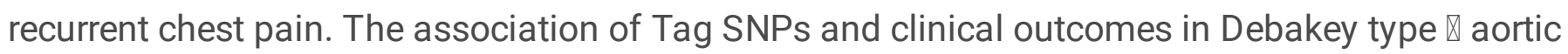
dissection patients were assessed by Kaplan-Meier method, the log-rank test (Figure 1). Patients with these genotypes are associated with a higher mortality risk: dominant models of MYH11 rs115364997 AG+GG genotype (HR = 2.443; 95\%Cl:1.096-5.445, $P=0.029)$, TGFB1 rs1800469 AG+GG (HR = 2.303; 95\%Cl:1.069-4.96, $P=0.033$ ), and additive models of MYH11 rs115364997 (AG vs. AA) (HR= 2.754; $95 \% \mathrm{Cl}: 1.187-6.391, P=0.018)$, TGFB1 rs1800469 (AG vs. AA) $(\mathrm{HR}=2.893 ; 95 \% \mathrm{Cl}: 1.241-6.448, P=$ $0.013)$. No statistically differences were found between mortality risk and genetic models of MYH11 rs117593370, TGFBR1 rs1626340 $(P>0.05)$ (Table 6).

The same statistical methods were used in risk of recurrent chest pain. As a result, TGFB1 rs1800469 dominant model $A G+G G$ genotype was found to be associated with a higher risk of recurrence of chest pain $(\mathrm{HR}=1.566 ; 95 \% \mathrm{Cl}: 1.018-2.378, P=0.041)$. No statistically differences were found between mortality risk and other genetic models $(P>0.05)$ (Table 7$)$.

\section{Discussion}

Aortic dissection is a complex multifactorial disease influenced by genetic and environmental factors $[19,20]$. Single gene mutation is not the determinant of $A D$, while interaction of multiple genes and environment may result in a higher risk of AD [21]. Therefore, MYH11 and TGF- $\beta$ pathway-related gene about structure and function of SMCs were discussed in this study to assessing whether genetic variation, environmental factors and their interaction are associated with the risk of Debakey type III AD and poor prognosis.

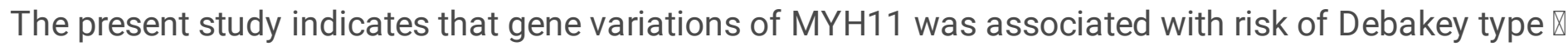
AD and high mortality. The mutation site of MYH11 rs115364997 located in the intron region. Recent studies [22] indicate that mutations in some intron regions are mainly involved in expression regulation and selective splicing, mutations in different splicing sites cause mRNA shearing Cleavage leads to the 
change of protein sequence and function. Previous studies suggested that mutations in MYH11 are identified in patients with aortic aneurysm/dissection [9]. This mutation result in a defective contractile apparatus and the proliferation of SMCs that do not produce contractile proteins in the aortic media. Then, it further leads to the contraction dysfunction of SMCs and lower the reduction of aortic compliance and elasticity. In addition, Larson et al. [23] found that MYH11 gene mutation is also associated with patent ductus arteriosus and intracranial artery disease $邓$ which shown that MYH11 plays a key role in maintaining the stability of blood vessel walls. Mutations in the MYH11 gene results in abnormal structure or function of myosin, which in turn leads to smooth muscle contraction dysfunction and impaired vascular stability.

In this study, we found that the TGFBR1 and TGFB1 gene variants were associated with the risk of Debakey type $\triangle A D$ and poor prognostic risks, respectively. Previous studies suggested that FTAAD and Marfan syndrome patients with TGFBR1 mutation have low expression of smooth muscle contractile protein [24,25]; TGFBR1 deficiency mice rapidly formed serious aortic dissection [17]. In an UK cohort study, the TGFBR1 rs1626340 AA genotype was found to have a higher proportion of abdominal aortic aneurysms [26]. And genetic variations in TGFBR1 rs1626340 are also associate with abdominal aortic aneurysm in a Dutch population[27] and intracranial aneurysm [28]. According to our results, that carriers of the TGFBR1 rs1626340 A allele, but not TGFB1 rs1800469 alleles or genotypes, were likely to a higher risk of DeBakey type III aortic dissection. On the contrary, Zuo et al [29] have demonstrated that the recessive model and additive model of TGFB1 rs1800469 are related to abdominal aortic aneurysm, but not TGFBR1 rs1626340 genotypes or genetic models. Therefore, the dysfunction of TGF- $\beta$ signaling transduction may lead to aortic aneurysm/dissection through different molecular processes. Furthermore, Kaplan-Meier analysis from present study indicate that carriers of the AG genotype of the dominant model of TGFB1rs1800469 have a higher risk of death and chest pain recurrence, which may be related to the aortic dilation and the continuous progression of aortic dissection. A meta-analysis demonstrated a significant association of the latent TGF- $\beta$ binding protein 4 (LTBP4) 21011 A > T genotype and abdominal aortic aneurysms growth [26]. A multicenter from around the world study found that patients with a TGFBR1 mutations have $80 \%$ survival rate at 60 years, and $23 \%$ aortic dissection risk [30]. However, there has been no study other than ours on the association between TGF- $\beta$ signaling-related genetic polymorphism and aortic dissection outcomes after surgery.

In addition, GMDR analysis shown that there were interactions between MYH11rs115364997, TGF- $\beta$ related-gene polymorphism and environmental factors, affecting AD. The results of Zuo et al. [29] about TGFB1 gene polymorphism and environmental factors interactions worked together in abdominal aortic aneurysm risk, which are similar in this study. TGF- $\beta$ signaling is found in non-syndromic aortic disease caused by MYH11 mutations and undefined etiology[31].TGF- $\beta$ causes the contraction of smooth muscle cells that is shown by continuously increasing the level of related contractile proteins (including MYH11). In turn, mutations of the MYH11 may also be associated with upregulation of TGF- $\beta$ signaling, which is implicated in Marfan syndrome and TAA formation. MYH11 is regulated by Smads, a downstream signal of TGFBRs. Mutations in MYH11 will lead to abnormalities in myosin, leading to defects in the assembly of fibronectin fibrils on the cell surface. This in turn causes fibrin-1 to assemble into microfibrils making 
TGF- $\beta$ signaling easier to activate and leading to an increase in the number of nuclear phosphorylated Smad2[15]. In addition, studies have shown that smoking, drinking, obesity, and hyperlipidemia are the risk factors of AD [32-34]. Nicotine in tobacco stimulates blood vessels, causing abnormal proliferation of smooth muscle cells to produce inflammatory reactions and other effects, leading to the formation of aortic dissection [35]. Ethanol consumption may reduce the vasodilation caused by Adrenomedullin, leading to vascular dysfunction and hypertension [36].

Limitations of this study: aortic dissection is a polygenic genetic disease regulated by multiple signaling pathway, more genes on other signaling pathways should be discussed. Secondly, it is necessary to study the mechanism of protein or cells aspects in AD patients. Third, the subjects in this study come from the same hospital, and may have selection bias, which could not better represent the general population.

\section{Conclusions}

According to our results, MYH11 rs115364997 and TGFBR1 rs1626340 SNPs are associated with genetic predisposition of DeBakey type III AD. MYH11 rs115364997 and TGFB1 rs1800469 genetic polymorphisms maybe a prognostic indicator, especially in motility and recurrence of chest pain for DeBakey type III aortic dissection. The interaction between MYH11, TGF- $\beta$ pathway-related genetic polymorphisms and environmental factors may associated with DeBakey type III aortic dissection.

\section{Declarations}

\section{Acknowledgements}

Not available

\section{Authors' contributions}

YM and XM designed the work and revised the manuscript; YC, QY, PJ and LS collected all clinical data and participated in conceiving the work; $Y C$ and QY drafted and revised the manuscript. The authors have approved the final manuscript.

\section{Funding}

This work was funded by the National Natural Science Foundation of China (N0.81660085).

\section{Availability of data and materials}

The datasets used and/or analyzed during the current study are available from the corresponding author on reasonable request.

\section{Ethics approval and consent to participate}


This study was approved by the Ethics Committee of The First Affiliated Hospital of Xinjiang Medical University.

\section{Consent for publication}

All participants consented to the publication of their data.

\section{Competing interests}

All authors have declared no conflicts of interest.

\section{References}

1. Mcclure R S, Brogly S B, Lajkosz K, et al. Epidemiology and management of thoracic aortic dissections and thoracic aortic aneurysms in Ontario, Canada, A population-based study. Journal of Thoracic \& Cardiovascular Surgery. 2018; 6:2254-2264.

2. Arman, Kilic, Ashish, et al. Trends in repair of intact and ruptured descending thoracic aortic aneurysms in the United States, A population-based analysis. Journal of Thoracic \& Cardiovascular Surgery. 2014;6:1855-1860.

3. Piechota-Polanczyk A, Jozkowicz A, Nowak W, et a1. The Abdominal Aortic Aneurysm and Intraluminal Thrombus, Current Concepts of Development and Treatment. Front Cardiovasc Med. $2015 ; 26: 2,19$.

4. Takeda N, Komuro I. Genetic basis of hereditary thoracic aortic aneurysms and dissections. Journal of Cardiology. 2019; 2:136-143.

5. Sakai L Y, Keene D R, Renard M, et al. FBN1, The disease-causing gene for Marfan syndrome and other genetic disorders. Gene. 2016; 1:279-291.

6. Utako Y, Noriaki A, Ryo I, et al. Proteomic analysis of aortic smooth muscle cell secretions reveals an association of myosin heavy chain 11 with abdominal aortic aneurysm. Am J Physiol Heart Circ Physiol. 2018; 315(4):1012-1018.

7. Karimi A, Milewicz DM. Structure of the Elastin-Contractile Units in the Thoracic Aorta and How Genes That Cause Thoracic Aortic Aneurysms and Dissections Disrupt This Structure. Can J Cardiol. 2016; 32(1):26-34.

8. Harakalova M, van der Smagt J, de Kovel CG, et al. Incomplete segregation of MYH11 variants with thoracic aortic aneurysms and dissections and patent ductus arteriosus. Eur J Hum Genet. 2013; 21(5):487-493.

9. Renard M1, Callewaert B, Baetens M, et al. Novel MYH11 and ACTA2 Mutations Reveal a Role for Enhanced TGF $\beta$ Signaling in FTAAD. Int J Cardiol. 2013; 2: 314-321.

10. Frismantiene A, Philippova M, Erne P, et al. Smooth muscle cell-driven vascular diseases and molecular mechanisms of VSMC plasticity. Cell Signal. 2018; 52:48-64. 
11. Haize G, Maria F, Reyes V M, et al. Characterization of Carotid Smooth Muscle Cells during Phenotypic Transition. Cells. 2018; 3: 23-25.

12. Goumans, Marie-José, Ten Dijke P. TGF- $\beta$ Signaling in Control of Cardiovascular Function. Cold Spring Harbor Perspectives in Biology. 2018; 2: a022210.

13. Gao F, Chambon P, Offermanns $S$, et al. Disruption of TGF- $\beta$ signaling in smooth muscle cell prevents elastase-induced abdominal aortic aneurysm. Biochemical \& Biophysical Research Communications. 2014; 1:137-143.

14. Li W, Li Q, Jiao Y, et al. Tgfbr2 disruption in postnatal smooth muscle impairs aortic wall homeostasis. Journal of Clinical Investigation. 2014; 2: 755-767.

15. De Cario R, Sticchi E, Lucarini L, et al. Role of TGFBR1 and TGFBR2 genetic variants in Marfan syndrome. Journal of Vascular Surgery. 2018; 1: 225-233.e5.

16. Isselbacher E M, Lino Cardenas C L, Lindsay M E. Hereditary Influence in Thoracic Aortic Aneurysm and Dissection. Circulation. 2016; 133,2516-2528.

17. Yang P, Schmit B M, Fu C, et al. Smooth muscle cell-specific Tgfbr1 deficiency promotes aortic aneurysm formation by stimulating multiple signaling events. Scientific Reports. 2016; 6:35444.

18. Xu HM, Xu LF, Hou TT, et al. GMDR, Versatile Software for Detecting Gene-Gene and GeneEnvironment Interactions Underlying Complex Traits. Curr Genomics. 2016; 17(5):396-402.

19. Ito S, Akutsu K, Tamori Y, et al. Differences in atherosclerotic profiles between patients with thoracic and abdominal aortic aneurysms. The American journal of cardiology. 2008; 101: 696-699.

20. Mussa FF, Horton JD, Moridzadeh R, et al. Acute Aortic Dissection and Intramural Hematoma, A Systematic Review. JAMA. 2016; 316: 754-763.

21. Adam B, Valentyna K, Bulat Z, et al. Genes Associated with Thoracic Aortic Aneurysm and Dissection, An Update and Clinical Implications. Aorta. 2018; 06: 013-020.

22. Jacob AG, Smith CWJ. Intron retention as a component of regulated gene expression programs. Hum Genet. 2017; 136:1043-1057.

23. Larson A, Rinaldo L, Brinjikji W, et al. Intracranial Vessel Stenosis in a Young Patient with an MYH11 Mutation, A Case Report and Review of 2 Prior Cases. World Neurosurgery. 2020; 137:243-246.

24. Norifumi T, Hironori $H$, Takayuki F, et al. TGF- $\beta$ Signaling-Related Genes and Thoracic Aortic Aneurysms and Dissections. Int J of Mol Sci. 2018; 19:2125.

25. Franken R, den Hartog AW, Radonic T. Beneficial outcome of losartan therapy depends on type of fbn 1 mutation in marfan syndrome. Circulation Cardiovascular genetics. 2015; 8:383-388.

26. Thompson AR, Cooper JA, Jones GT, et al. Assessment of the association between genetic polymorphisms in transforming growth factor beta, and its binding protein (LTBP), and the presence, and expansion, of Abdominal Aortic Aneurysm. Atherosclerosis. 2010; 209(2):367-373.

27. Baas AF, Medic J, van 't Slot R, et al. Association of the TGF-beta receptor genes with abdominal aortic aneurysm. Eur J Hum Genet. 2010; 18(2):240-244. 
28. Ruigrok YM, Baas AF, Medic J, et al. The transforming growth factor- $\beta$ receptor genes and the risk of intracranial aneurysms. Int J Stroke. 2012; 7(8):645-648.

29. Zuo S, Xiong J, Wei Y, et al. Potential Interactions Between Genetic Polymorphisms of the Transforming Growth Factor- $\beta$ Pathway and Environmental Factors in Abdominal Aortic Aneurysms. Eur J Vasc Endovasc Surg. 2015; 50(1):71-77.

30. Jondeau G, Ropers J, Regalado E, et al. International Registry of Patients Carrying TGFBR1 or TGFBR2 Mutations, Results of the MAC (Montalcino Aortic Consortium; Circ Cardiovasc Genet. 2016; 9(6):548-558.

31. Gomez D, Al Haj Zen A, Borges LF, et al. Syndromic and non-syndromic aneurysms of the human ascending aorta share activation of the Smad2 pathway. J Pathol. 2009; 218(1):131-142.

32. Feldo M, Kocki J, Feldo J, et al. CIDE-A gene expression in patients with obesity qualified for endovascular treatment of abdominal aorta aneurysm. Pol Przegl Chir. 2015; 86(10):473-478.

33. Yoshiyama S, Chen Z, Okagaki T, et al. Nicotine exposure alters human vascular smooth muscle cell phenotype from a contractile to a synthetic type. Atherosclerosis. 2014; 237: 464-470.

34. Kim JB, Kim K, Lindsay ME, et al. Risk of Rupture or Dissection in Descending Thoracic Aortic Aneurysm. Circulation. 2015; 132: 1620-1629.

35. Zhu J, Liu B, Wang Z, et al. Exosomes from nicotine-stimulated macrophages accelerate atherosclerosis through miR-21-3p/PTEN-mediated VSMC migration and proliferation. Theranostics. 2019; 9: 6901-6919.

36. Hipólito UV, Rocha JT, Martins-Oliveira A et al. Chronic ethanol consumption reduces adrenomedullininduced relaxation in the isolated rat aorta. Alcohol. 2011;45(8):805-814.

\section{Tables}

Table 1 General characteristics between case and control subjects. 


\begin{tabular}{|c|c|c|c|}
\hline Characteristics & Case $(\mathrm{N}=173)$ & Control(N=335) & $P$ \\
\hline Age(years) & $51.54 \pm 11.53$ & $57.12 \pm 11.39$ & $\otimes 0.001$ \\
\hline Male (male, \%) & 144(83.2) & 193(57.6) & $\triangle 0.001$ \\
\hline $\mathrm{SBP}(\mathrm{mmHg})$ & $154.04 \pm 30.37$ & $126.23 \pm 17.94$ & $\otimes 0.001$ \\
\hline $\mathrm{DBP}(\mathrm{mmHg})$ & $87.89 \pm 18.31$ & $77.19 \pm 12.04$ & $\nabla 0.001$ \\
\hline $\mathrm{BMI}\left(\mathrm{kg} / \mathrm{m}^{2}\right)$ & $27.0 \pm 4.23$ & $25.3 \pm 3.33$ & $₫ 0.001$ \\
\hline WBC $\left(10^{\wedge} 9 / L\right)$ & $11.59 \pm 4.17$ & $6.35 \pm 1.87$ & $\nabla 0.001$ \\
\hline $\mathrm{BUN}(\mathrm{mmol} / \mathrm{L})$ & $6.23 \pm 3.56$ & $5.42 \pm 4.82$ & 0.053 \\
\hline Creatinine (umol/L) & $92.1 \pm 94.81$ & $70.43 \pm 19.69$ & 0.003 \\
\hline Uric acid (umol/L) & $336.52 \pm 108.16$ & $309.45 \pm 89.77$ & 0.005 \\
\hline Glucose (mmol/L) & $7.20 \pm 2.40$ & $5.52 \pm 1.78$ & $\nabla 0.001$ \\
\hline $\mathrm{GSP}(\mathrm{mmol} / \mathrm{L})$ & $2.01 \pm 0.36$ & $2.26 \pm 0.51$ & $\otimes 0.001$ \\
\hline Triglyceride $(\mathrm{mmol} / \mathrm{L})$ & $1.56 \pm 0.88$ & $1.54 \pm 0.72$ & 0.854 \\
\hline Total cholesterol (mmol/L) & $4.21 \pm 1.01$ & $4.22 \pm 1.07$ & 0.935 \\
\hline $\mathrm{HDL}-\mathrm{C}(\mathrm{mmol} / \mathrm{L})$ & $1.05 \pm 0.49$ & $1.16 \pm 0.45$ & 0.015 \\
\hline LDL-C (mmol/L) & $2.62 \pm 0.77$ & $2.66 \pm 1.19$ & 0.692 \\
\hline Hypertension (n, \%) & $136(78.61)$ & $143(42.69)$ & $\nabla 0.001$ \\
\hline Diabetes (n, \%) & $10(5.78)$ & $27(8.06)$ & 0.035 \\
\hline Smoking $(\mathrm{n}, \%)$ & $102(58.96)$ & $79(23.58)$ & $\nabla 0.001$ \\
\hline Drinking $(\mathrm{n}, \%)$ & $89(51.45)$ & $56(16.72)$ & $\otimes 0.001$ \\
\hline
\end{tabular}

SBP, systolic blood pressure; DBP, diastolic blood pressure; BMI, body mass index; WBC, white blood cell; BUN, blood urea nitrogen; GSP, Glycosylated serum protein; HDL-C, high density lipoprotein cholesterol; LDL-C, low density lipoprotein cholesterol.

Table 2 Description for genotype and allele frequencies in case and control group 


\begin{tabular}{|c|c|c|c|c|}
\hline SNP & Genotype/Allele & Case, n (\%) & Control, n (\%) & $P$ \\
\hline \multirow[t]{5}{*}{ rs115364997 } & AA & 119(68.8) & 262(78.2) & 0.044 \\
\hline & $A G$ & $47(27.2)$ & $67(20.0)$ & \\
\hline & GG & $7(4.0)$ & $6(1.8)$ & \\
\hline & $A$ & $285(82.4)$ & $591(88.2)$ & 0.011 \\
\hline & G & 61(17.6) & 79(11.8) & \\
\hline \multirow[t]{5}{*}{ rs117593370 } & $\mathrm{CC}$ & 159(91.9) & $316(68.8)$ & 0.577 \\
\hline & $\mathrm{CT}$ & $11(6.4)$ & $15(27.2)$ & \\
\hline & $\mathrm{TT}$ & $3(1.7)$ & $4(4.0)$ & \\
\hline & C & $329(95.1)$ & $647(96.6)$ & 0.250 \\
\hline & $\mathrm{T}$ & $17(4.9)$ & $23(3.4)$ & \\
\hline \multirow[t]{5}{*}{ rs1800469 } & $\mathrm{AA}$ & $61(35.3)$ & 101(30.1) & 0.466 \\
\hline & $A G$ & $78(45.1)$ & $158(47.2)$ & \\
\hline & $\mathrm{GG}$ & $34(19.7)$ & $76(22.7)$ & \\
\hline & A & $200(57.8)$ & $360(53.7)$ & 0.216 \\
\hline & G & $146(42.2)$ & $310(46.3)$ & \\
\hline \multirow[t]{5}{*}{ rs1626340 } & AA & 23(13.3) & $52(15.5)$ & 0.030 \\
\hline & GA & $84(48.6)$ & $122(36.4)$ & \\
\hline & GG & $66(38.2)$ & $161(48.1)$ & \\
\hline & $A$ & 130(37.6) & 226(33.7) & 0.224 \\
\hline & G & $216(62.4)$ & $444(66.3)$ & \\
\hline
\end{tabular}

Table 3 Analysis of the association between genetic models and aortic dissection risk 


\begin{tabular}{|c|c|c|c|c|c|}
\hline SNP & Genetic Model & Genotype & OR & $95 \% \mathrm{Cl}$ & $P$ \\
\hline \multirow[t]{5}{*}{ rs115364997 } & Dominant & $(A G+G G) / A A$ & 1.629 & $1.077-2.462$ & 0.020 \\
\hline & Recessive & $\mathrm{GG} /(\mathrm{AA}+\mathrm{AG})$ & 2.312 & $0.765-6.990$ & 0.127 \\
\hline & Additive & AA & 1.000 & & \\
\hline & & $A G$ & 1.544 & $1.003-2.377$ & 0.047 \\
\hline & & GG & 2.569 & $0.845-7.808$ & 0.086 \\
\hline \multirow[t]{5}{*}{ rs117593370 } & Dominant & $(\mathrm{CT}+\mathrm{TT}) / \mathrm{CC}$ & 1.464 & $0.716-2.997$ & 0.294 \\
\hline & Recessive & $\mathrm{TT} /(\mathrm{CC}+\mathrm{CT})$ & 1.46 & $0.323-6.599$ & 0.621 \\
\hline & Additive & $\mathrm{CC}$ & 1.000 & & \\
\hline & & СT & 1.457 & $0.654-3.247$ & 0.354 \\
\hline & & TT & 1.491 & $0.330-6.741$ & 0.602 \\
\hline \multirow[t]{5}{*}{ rs1800469 } & Dominant & $(A G+G G) / A A$ & 0.792 & $0.537-1.170$ & 0.241 \\
\hline & Recessive & $\mathrm{GG} /(\mathrm{AA}+\mathrm{AG})$ & 0.834 & $0.529-1.312$ & 0.432 \\
\hline & Additive & AA & 1.000 & & \\
\hline & & $A G$ & 0.817 & $0.538-1.241$ & 0.344 \\
\hline & & GG & 0.741 & $0.443-1.239$ & 0.252 \\
\hline \multirow[t]{5}{*}{ rs1626340 } & Dominant & $(G A+A A) / G G$ & 1.500 & $1.032-2.181$ & 0.033 \\
\hline & Recessive & $A A /(G G+G A)$ & 0.834 & $0.492-1.417$ & 0.502 \\
\hline & Additive & GG & 1.000 & & \\
\hline & & GA & 1.68 & $1.127-2.503$ & 0.011 \\
\hline & & $\mathrm{AA}$ & 1.079 & $0.611-1.905$ & 0.793 \\
\hline
\end{tabular}

Table 4 Generalized multifactor dimensionality reduction analysis of gene-gene interactions and aortic dissection risk. 


\begin{tabular}{|lllll|}
\hline Model & $\begin{array}{l}\text { Training } \\
\text { Bal. Acc }\end{array}$ & $\begin{array}{l}\text { Testing } \\
\text { Bal. Acc }\end{array}$ & $\begin{array}{l}\text { Sign Test } \\
(\mathbf{p})\end{array}$ & $\begin{array}{l}\text { CV } \\
\text { Consistency }\end{array}$ \\
\hline TGFBR1rs1626340 & 0.5591 & 0.5134 & $6(0.3770)$ & $7 / 10$ \\
\hline MYH11rs115364997, TGFBR1rs1626340 & 0.5842 & 0.5600 & $9(0.0107)$ & $10 / 10$ \\
\hline $\begin{array}{l}\text { MYH11rs115364997, TGFB1rs1800469, } \\
\text { TGFBR1rs1626340 }\end{array}$ & 0.6604 & 0.5156 & $6(0.3770)$ & $10 / 10$ \\
\hline $\begin{array}{l}\text { MYH11rs15364997, MYH11rs17593370, } \\
\text { TGFB1rs1800469, TGFBR1rs1626340 }\end{array}$ & 0.6100 & 0.4845 & $5(0.6230)$ & $10 / 10$ \\
\hline
\end{tabular}

Table 5 Generalized multifactor dimensionality reduction analysis of geneenvironment interactions and aortic dissection risk.

\begin{tabular}{|c|c|c|c|c|}
\hline Model & $\begin{array}{l}\text { Training } \\
\text { Bal. } \\
\text { Acc. }\end{array}$ & $\begin{array}{l}\text { Testing } \\
\text { Bal. } \\
\text { Acc. }\end{array}$ & $\begin{array}{l}\text { Sign } \\
\text { Test }(p)\end{array}$ & $\begin{array}{l}\text { CV } \\
\text { Consistency }\end{array}$ \\
\hline Smoking & 0.6891 & 0.6772 & $\begin{array}{l}10 \\
(0.0010)\end{array}$ & $9 / 10$ \\
\hline Drinking, $\mathrm{BMI} \geq 24 \mathrm{~kg} / \mathrm{m}^{2}$ & 0.7567 & 0.7447 & $\begin{array}{l}10 \\
(0.0010)\end{array}$ & $10 / 10$ \\
\hline Smoking, hypertension, $\mathrm{BMI} \geq 24 \mathrm{~kg} / \mathrm{m}^{2}$ & 0.7712 & 0.7374 & $\begin{array}{l}10 \\
(0.0010)\end{array}$ & $7 / 10$ \\
\hline Smoking, drinking, hypertension, $\mathrm{BMI} \geq 24 \mathrm{~kg} / \mathrm{m}^{2}$ & 0.8010 & 0.7763 & $\begin{array}{l}10 \\
(0.0010)\end{array}$ & $9 / 10$ \\
\hline $\begin{array}{l}\text { TGFB1rs1800469, TGFBR1rs1626340, smoking, } \\
\text { hypertension, BMI } \geq 24 \mathrm{~kg} / \mathrm{m}^{2}\end{array}$ & 0.8261 & 0.7458 & $\begin{array}{l}10 \\
(0.0010)\end{array}$ & $8 / 10$ \\
\hline $\begin{array}{l}\text { TGFB1rs1800469, TGFBR1rs1626340, smoking, } \\
\text { drinking, hypertension, BMI } \geq 24 \mathrm{~kg} / \mathrm{m}^{2}\end{array}$ & 0.8649 & 0.7665 & $\begin{array}{l}10 \\
(0.0010)\end{array}$ & $10 / 10$ \\
\hline $\begin{array}{l}\text { MYH11rs115364997, TGFB1rs1800469, } \\
\text { TGFBR1rs1626340, smoking, drinking, } \\
\text { hypertension, BMI } \geq 24 \mathrm{~kg} / \mathrm{m}^{2}\end{array}$ & 0.8940 & 0.7673 & $\begin{array}{l}10 \\
(0.0010)\end{array}$ & $10 / 10$ \\
\hline $\begin{array}{l}\text { MYH11rs115364997, TGFB1rs1800469, } \\
\text { TGFBRIrs1626340, smoking, drinking, hypertension, } \\
\text { BMI } \geq 24 \mathrm{~kg} / \mathrm{m}^{2} \text {, dyslipidemia }\end{array}$ & 0.9212 & 0.7554 & $\begin{array}{l}10 \\
(0.0010)\end{array}$ & $10 / 10$ \\
\hline $\begin{array}{l}\text { MYH11rs115364997, MYH11 rs117593370, } \\
\text { TGFB1rs1800469, TGFBRIrs1626340, smoking, } \\
\text { drinking, hypertension, BMI } \geq 24 \mathrm{~kg} / \mathrm{m}^{2} \text {, dyslipidemia }\end{array}$ & 0.9251 & 0.7261 & $\begin{array}{l}10 \\
(0.0010)\end{array}$ & $7 / 10$ \\
\hline
\end{tabular}


Table 6 Association between Tag SNPs and mortality risk in DeBakey type $\square$ aortic dissection patients

\begin{tabular}{|c|c|c|c|c|c|c|}
\hline SNPs & Genetic Model & Genotype & $x^{2}$ & $P$ & HR & $95 \% \mathrm{Cl}$ \\
\hline \multirow[t]{5}{*}{ rs115364997 } & Dominant & $(A G+G G) / A A$ & 4.770 & 0.029 & 2.443 & $1.096-5.445$ \\
\hline & Recessive & $G G /(A A+A G)$ & 0.036 & 0.850 & 0.838 & $0.135-5.211$ \\
\hline & Additive & AA & & & 1.000 & \\
\hline & & $A G$ & 5.561 & 0.018 & 2.754 & $1.187-6.391$ \\
\hline & & GG & 0.029 & 0.864 & 1.211 & $0.135-10.85$ \\
\hline \multirow[t]{5}{*}{ rs117593370 } & Dominant & $(\mathrm{CT}+\mathrm{TT}) / \mathrm{CC}$ & 0.027 & 0.869 & 0.891 & $0.227-3.505$ \\
\hline & Recessive & $\mathrm{TT} /(\mathrm{CC}+\mathrm{CT})$ & 0.506 & 0.477 & 0.361 & $0.022-5.986$ \\
\hline & Additive & $\mathrm{CC}$ & & & 1.000 & \\
\hline & & CT & 0.031 & 0.859 & 1.148 & $0.25-5.267$ \\
\hline & & TT & 0.498 & 0.481 & 0.361 & $0.212-6.133$ \\
\hline \multirow[t]{5}{*}{ rs1800469 } & Dominant & $(A G+G G) / A A$ & 4.544 & 0.033 & 2.303 & $1.069-4.96$ \\
\hline & Recessive & $G G /(A A+A G)$ & 0.134 & 0.715 & 0.843 & $0.337-2.108$ \\
\hline & Additive & AA & & & 1.000 & \\
\hline & & $A G$ & 6.124 & 0.013 & 2.893 & $1.241-6.448$ \\
\hline & & GG & 0.812 & 0.368 & 1.810 & $0.498-6.585$ \\
\hline \multirow[t]{5}{*}{ rs1626340 } & Dominant & $(\mathrm{GA}+\mathrm{AA}) / \mathrm{GG}$ & 0.440 & 0.507 & 0.771 & $0.358-1.662$ \\
\hline & Recessive & $\mathrm{AA} /(\mathrm{GG}+\mathrm{GA})$ & 0.689 & 0.406 & 1.603 & $0.526-4.888$ \\
\hline & Additive & GG & & & 1.000 & \\
\hline & & GA & 0.895 & 0.344 & 0.671 & $0.293-1.534$ \\
\hline & & AA & / & l & / & / \\
\hline
\end{tabular}

Table 7 Association between Tag SNPs and recurrent chest pain in DeBakey type $\square$ aortic dissection patients 


\begin{tabular}{|c|c|c|c|c|c|c|}
\hline SNPs & Genetic Model & Genotype & $x^{2}$ & $P$ & HR & $95 \% \mathrm{Cl}$ \\
\hline \multirow[t]{5}{*}{ rs115364997 } & Dominant & $(A G+G G) / A A$ & 0.056 & 0.813 & 1.054 & $0.679-1.638$ \\
\hline & Recessive & $\mathrm{GG} /(\mathrm{AA}+\mathrm{AG})$ & 0.016 & 0.901 & 0.945 & $0.387-2.304$ \\
\hline & Additive & AA & & & 1.000 & \\
\hline & & $A G$ & 0.084 & 0.772 & 1.072 & $0.671-1.714$ \\
\hline & & GG & 0.013 & 0.910 & 0.949 & $0.384-2.351$ \\
\hline \multirow[t]{5}{*}{ rs117593370 } & Dominant & $(\mathrm{CT}+\mathrm{TT}) / \mathrm{CC}$ & 0.158 & 0.691 & 1.201 & $0.488-2.953$ \\
\hline & Recessive & $\mathrm{TT} /(\mathrm{CC}+\mathrm{CT})$ & 1.101 & 0.294 & 0.360 & $0.054-2.425$ \\
\hline & Additive & $\mathrm{CC}$ & & & 1.000 & \\
\hline & & CT & 0.919 & 0.338 & 1.627 & $0.601-4.418$ \\
\hline & & TT & 1.100 & 0.294 & 0.360 & $0.534-2.428$ \\
\hline \multirow[t]{5}{*}{ rs1800469 } & Dominant & $(A G+G G) / A A$ & 4.165 & 0.041 & 1.566 & $1.018-2.378$ \\
\hline & Recessive & $\mathrm{GG} /(\mathrm{AA}+\mathrm{AG})$ & 1.556 & 0.212 & 0.731 & $0.447-1.196$ \\
\hline & Additive & AA & & & 1.000 & \\
\hline & & $A G$ & 7.912 & 0.005 & 1.949 & $1.226-3.100$ \\
\hline & & GG & 0.005 & 0.943 & 1.023 & $0.549-1.907$ \\
\hline \multirow[t]{5}{*}{ rs1626340 } & Dominant & $(G A+A A) / G G$ & 1.162 & 0.281 & 0.790 & $0.514-1.213$ \\
\hline & Recessive & $A A /(G G+G A)$ & 0.376 & 0.540 & 1.220 & $0.647-2.300$ \\
\hline & Additive & GG & & & 1.000 & \\
\hline & & GA & 1.715 & 0.190 & 0.739 & $0.470-1.612$ \\
\hline & & $\mathrm{AA}$ & 0.035 & 0.852 & 1.064 & $0.554-2.043$ \\
\hline
\end{tabular}

\section{Figures}


A

rs1800469 dominant model

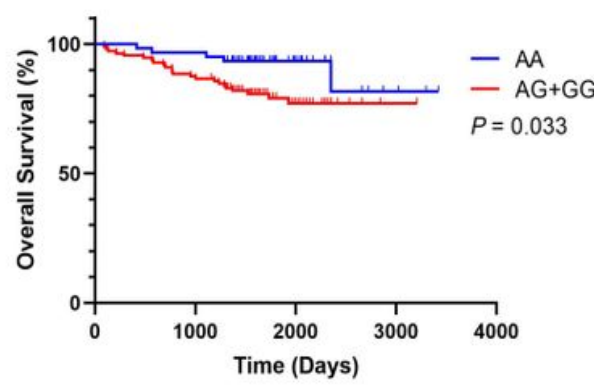

B

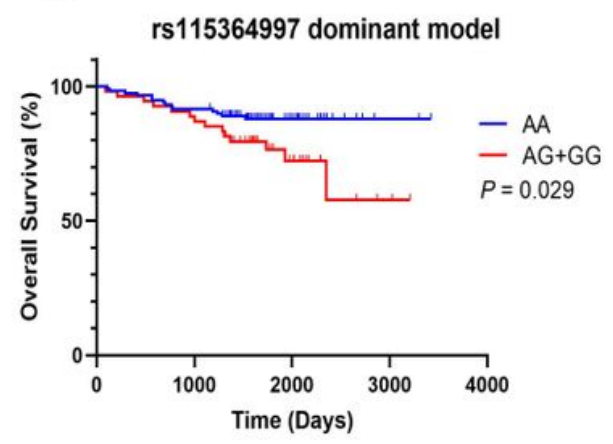

C

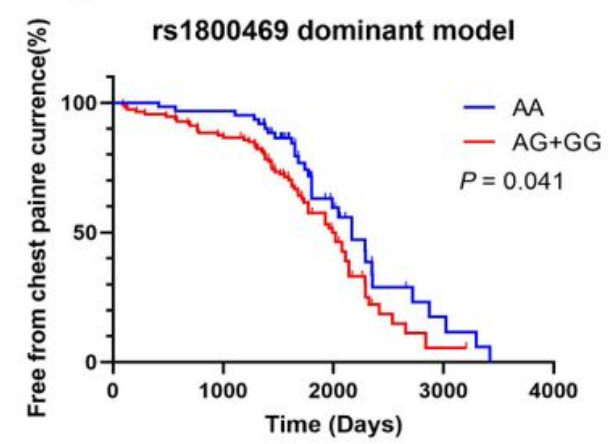

Figure 1

A. Kaplan-Meier analysis of overall survival based on MYH11 rs115364997 dominant model. B. KaplanMeier analysis of overall survival based on TGFB1 rs11800469 dominant model. C. Kaplan-Meier analysis of free from chest pain recurrence based on TGFB1 rs11800469 dominant model. 